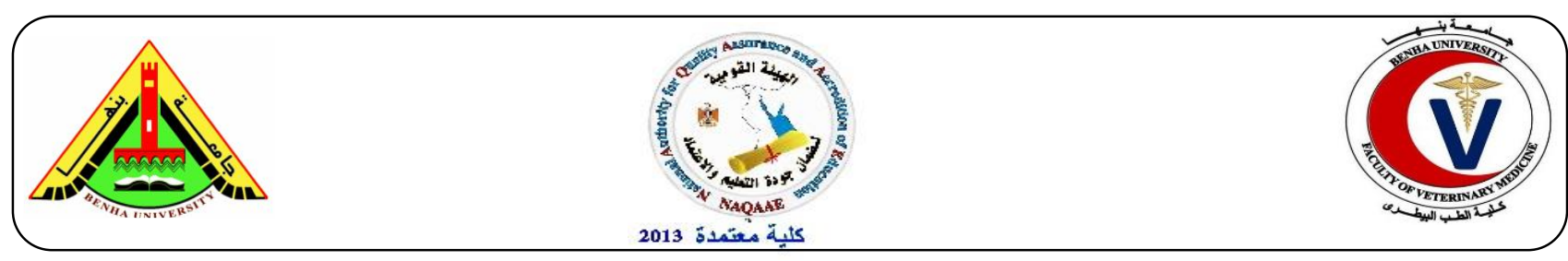

\title{
Antioxidant and anti-inflammatory effects of flaxseed oil and fish oil in fipronil induced oxidative stress in rats
}

Farrah, K.M.; Farid, A.S. and Mohammed A.K.

Department of Clinical Pathology, Faculty of Veterinary Medicine, Benha University

\section{A B S T R A C T}

The present study was designed to evaluate the antioxidant and inflammatory effect of flaxseed and fish oils in rats exposed to fipronil and bacterial wall containing lipopolysaccharides (LPSs). Sixty rats were divided into four groups each of 15 one. Group 1 served as control. Group 2, administered fipronil at dose of $15 \mathrm{mg} / \mathrm{kg}$ b.wt. orally for 15 days followed by single injection of LPSs $\left(2 \times 10^{6}\right.$ $\mathrm{CFU} /$ rat) intraperitonially at day $16^{\text {th }}$. Group 3, treated as group 2 plus administration of fish oil at dose of $270 \mathrm{mg} / \mathrm{kg}$ b.wt. orally daily all over the experimental period (30 days). Group 4, treated as group 2 plus administration of flaxseed oil at dose of $270 \mathrm{mg} / \mathrm{kg} \mathrm{b.wt}$. orally daily all over the experimental period. Serum was separated and used directly for determination of urea, creatinine, albumin, sodium, potassium, Tumor necrosis factor -alfa and Interleukin $1 \beta$. Kidney samples were taken for histopathological examination, Malondiadehyde (MDA), Glutathione peroxidase (GPx) and Superoxide dismutase (SOD). Results revealed that in group 2 there were significant elevations of urea, creatinine, MDA, TNF- $\alpha$ and IL-1 $\beta$. Furthermore, there were significant decreases in albumin, sodium, potassium, GPx and SOD compared with control group. Meanwhile, administration of flaxseed and fish oils resulted in significant decrease in urea, creatinine, MDA, TNF- $\alpha$ and IL-1 $\beta$ and significant increase in albumin, sodium, potassium, GPx and SOD compared with group 2. Therefore it's concluded that flaxseed and fish oils have strong antioxidant and antiinflammatory effects.

Keywords: Oxidative stress, Inflammation, Fipronil, Lipopolysaccharides, Flaxseed oil, Fish oil.

(http://www.bvmi.bu.edu.eg)

(BVMJ-35(2): 44-56, 2018)

\section{INTRODUCTION}

Oxidative stress is simply defined as a state in which oxidation exceeds the antioxidant systems in the body as a result of loss of harmony between them (Valko et al., 2006) while inflammation is considered an essential component of the immune response for fighting against pathogens invasion (Andrade et al., 2015 and Seki and Schwabe 2015). Several researches has documented that oxidative stress and inflammation are tightly interrelated in many diseases. They seem to occur simultaneously and also promote each other in injury site. In addition, continued oxidative stress can lead to chronic inflammation (Mittal et al., 2014).

Fipronil is the first member of the phenylpyrazole insecticide class with a broad spectrum action against insects, being used to 
control fleas, ticks, ants, cockroaches and other insects (Tingle et al., 2003). It can be responsible for increasing the production of reactive oxygen species (ROS) in cells, which in turn lead to increase lipid peroxidation levels and oxidative stress (Bolton et al., 2000).

On the other hand, LPSs are glycoprotein components of the cell wall of gram negative bacteria (Frudenberg and Galanos, 1990) and considered to be potent inducer of the host immune system resulting in overproduction of numerous pro- and anti-inflammatory cytokines in addition to an increase in oxidative stress (Takamiya et al., 2009).

Antioxidants suppress the process of oxidation by neutralizing free radicals. As a result, the antioxidants themselves become oxidized and this explains why there is a constant need to replenish our antioxidant resources (Goldfarb, 1993).

Plant products also are increasingly recognized to have protective roles owing to their antioxidant and anti-inflammatory properties in addition they do not have any adverse effects too (Lam et al., 2016 and Anilla and Vijayalaskshmi, 2002).

Fish oil has been widely studied as a complementary therapy for treatment of inflammatory diseases and inflammatory pain (Nobre et al., 2013) as well as in prevention of oxidative stress (Muga and Chao, 2014).

Vijaimohan et al., (2006) and Cohen et al., (2005) pointed to the anti-inflammatory properities of flaxseed oil while Newairy and Abdou (2009) illustrated its antioxidant effect and rendered this to being the richest source of lignans. Therefore, the aim of the present study was to evaluate the antioxidant and inflammatory effects of flaxseed and fish oils in rats exposed to fipronil and bacterial wall containing lipopolysaccharides (LPSs) through evaluation of some biochemical, antioxidant, anti-inflammatory parameters and histopathological changes in kidney tissue of rats.

\section{Materials and methods}

\subsection{Animals:}

Sixty white male albino rats weighing 170200 g. were used in the experimental investigation of this study. They were obtained from Laboratory Animals Research Center, Faculty of Veterinary Medicine, Moshtohor, Benha University. Rats were housed in separate metal cages with fresh and clean drinking water supplied ad libitum. Animals were kept at constant environmental and nutritional conditions throughout the experimental period. They were left 7 days for acclimatization before beginning the experiment.

\subsection{Chemicals and agents used in the experimental protocol:}

Lipopolysaccharides from killed E.coli: Escherichia coli (serotype O111) was obtained from Animal Health Research Institute, Benha branch. Lipopolysaccharides were obtained after killing E.coli strain.

Fipronil present in the form of liquid containing $20 \%$ fipronil under trade name (Fipromex 20\% SC) obtained from MACGMBH Company for Agricultural Products and Chemicals, Germany.

Fish oil present in the form of soft gelatine capsule obtained from South Egypt Drug Industries Co. (SEDICO), 6 October CityEgypt under trade name (Omega-3 plus)® with concentration of $1000 \mathrm{mg}$.

Flaxseed oil present in the form of soft gelatine capsule obtained from Medizen Pharmaceutical Industries for NAPHA under trade name (Flax seed oil) ® with concentration of $1000 \mathrm{mg}$.

\subsection{Expermintal design:}

Rats were divided into four groups each of 15 one placed in individual cages and 
classified as follow: Group 1 (Control), rats received no drugs, served as control for all experimental groups. Group 2, rats administered fipronil at dose of $15 \mathrm{mg} / \mathrm{kg}$ b.wt. orally for 15 days followed by single I.P. injection of LPSs $\left(2 \times 10^{6} \mathrm{CFU} / \mathrm{rat}\right)$ at day $16^{\text {th }}$. Group 3, rats administered fipronil at dose of $15 \mathrm{mg} / \mathrm{kg}$ b.wt. orally for 15 days followed by single I.P. injection of LPSs $(2 \times$ $10^{6} \mathrm{CFU} / \mathrm{rat}$ ) at day $16^{\text {th }}$ in addition to administration of fish oil at dose of 270 $\mathrm{mg} / \mathrm{kg}$ b.wt. orally daily (Hussein et al. 2013) all over the period of the experiment (30 days). Group 4, rats administered fipronil at dose of $15 \mathrm{mg} / \mathrm{kg}$ b.wt. orally for 15 days followed by single I.P. injection of LPSs $(2 \times$ $10^{6} \mathrm{CFU} /$ rat) at day $16^{\text {th }}$ in addition to administration of flaxseed oil at dose of 270 $\mathrm{mg} / \mathrm{kg}$ b.wt. orally daily (Hussein et al. 2014) all over the period of the experiment (30 days).

\subsection{Sampling:}

Blood samples for serum separation were collected from all animal groups at day $16^{\text {th }}$, $17^{\text {th }}$ and $30^{\text {th }}$ from retro-orbital venous plexus for separation of serum. Blood was collected in plain, clean well-dried centrifuge tubes for separation of serum to be used in quantitative determination of urea, creatinine, albumin, sodium, potassium, TNF- $\alpha$, IL-1 $\beta$. The collected blood samples were allowed to clot and serum samples were obtained by centrifugation at 3000 r.p.m. for 15 minutes. Sera were obtained by plastic aspiration pipette and transferred into clean, dry and labeled eppendorf tubes and kept in deep freeze till examination.

Kidney tissue specimens were collected at day $16^{\text {th }}$ and $30^{\text {th }}$ from all rats that were sacrificed by cervical decapitation. Kidney specimens were quickly removed, part of it preserved in clean, dry, labeled Eppendorf tubes and kept at $-20^{\circ} \mathrm{C}$ for MDA, SOD, and GPx determination. The other part was preserved in neutral buffered formalin solution (10\%) for histopathological examination. The specimens were dehydrated in different grades of ethyl alcohol, cleared in xylene, embedded in paraffin then sectioned to 6 microns and stained by hematoxylin and eosin stain.

\subsection{Biochemical analysis:}

Serum urea, creatinine and albumin concentration were determined according to the methods described by Kaplan (1984), Jaffe (1986) and Young (1995) respectively. Also serum sodium and potassium concentrations were determined according to the method described by Henry (1974).

MDA, GPx, SOD, TNF- $\alpha$ and IL- $1 \beta$ were determined by Enzyme Linked ImmunoSorbent Assay (ELISA).

\subsection{Statistical analysis:}

Data obtained were statistically evaluated for the mean and standard error (S.E). Statistical analysis was performed with statistical package for the social science (SPSS) software. $p<0.05$ was considered statistically significant. Over all differences between groups were determined by one - way ANOVA.

\section{RESULTS}

The results presented in table (1) revealed that rats treated with fipronil + lipopolysaccharides showed significant increases in serum urea and creatinine concentrations at day $16^{\text {th }}, 17^{\text {th }}$ and $30^{\text {th }}$ when compared with control rats. Meanwhile treatment with fish and flaxseed oils caused significant decrease in all measured parameters levels. A significant decrease in serum albumin, sodium and potassium concentrations were observed at day $16^{\text {th }}, 17^{\text {th }}$ and $30^{\text {th }}$ when compared with control rats while treatment with fish and flaxseed oils caused a significant increase in the value of parameters determined. 
The obtained results demonstrated in table (2) revealed that, rats treated with fipronil + lipopolysaccharides showed significant increases in L-MDA level with marked decrease in SOD and GPx activities in kidney tissue at day $16^{\text {th }}$ and $30^{\text {th }}$ when compared with control rats. In comparison with rats of group (2), rats treated with fish oil (group 3) and flaxseed oil (group 4) showed significant decrease in L-MDA level and marked increase in SOD and GPx activities in kidney tissue.

The current results illustrated in table (3) revealed that rats treated with fipronil + lipopolysaccharides caused significant increases in serum TNF- $\alpha$ and IL-1 $\beta$ concentrations at day $17^{\text {th }}$ when compared with control rats. However, treatment with fish and flaxseed oils showed significant decrease in the values of these parameters.

The histopathological findings in group (2) showed congestion in the cortical inter tubular blood vessels and tufts of the glomeruli associated with focal inflammatory cells infiltration in between the degenerated tubules (fig. 2). Meanwhile treatment with fish oil decreased the toxic effects and showed congestion in the renal blood vessels and intertubular blood capillaries (fig. 3), while treatment with flaxseed oil showed mild degenerative changes which manifested by vesiculation of glomerular tuft and mild degeneration of the epithelial cells lining the renal tubules

(fig.

4).

Table 1: Changes in serum biochemical parameters in control, Fipronil + lipopolysaccharides treated group, fish oil and flaxseed oil treated groups at day $16^{\text {th }}, 17^{\text {th }}$ and $30^{\text {th }}$.

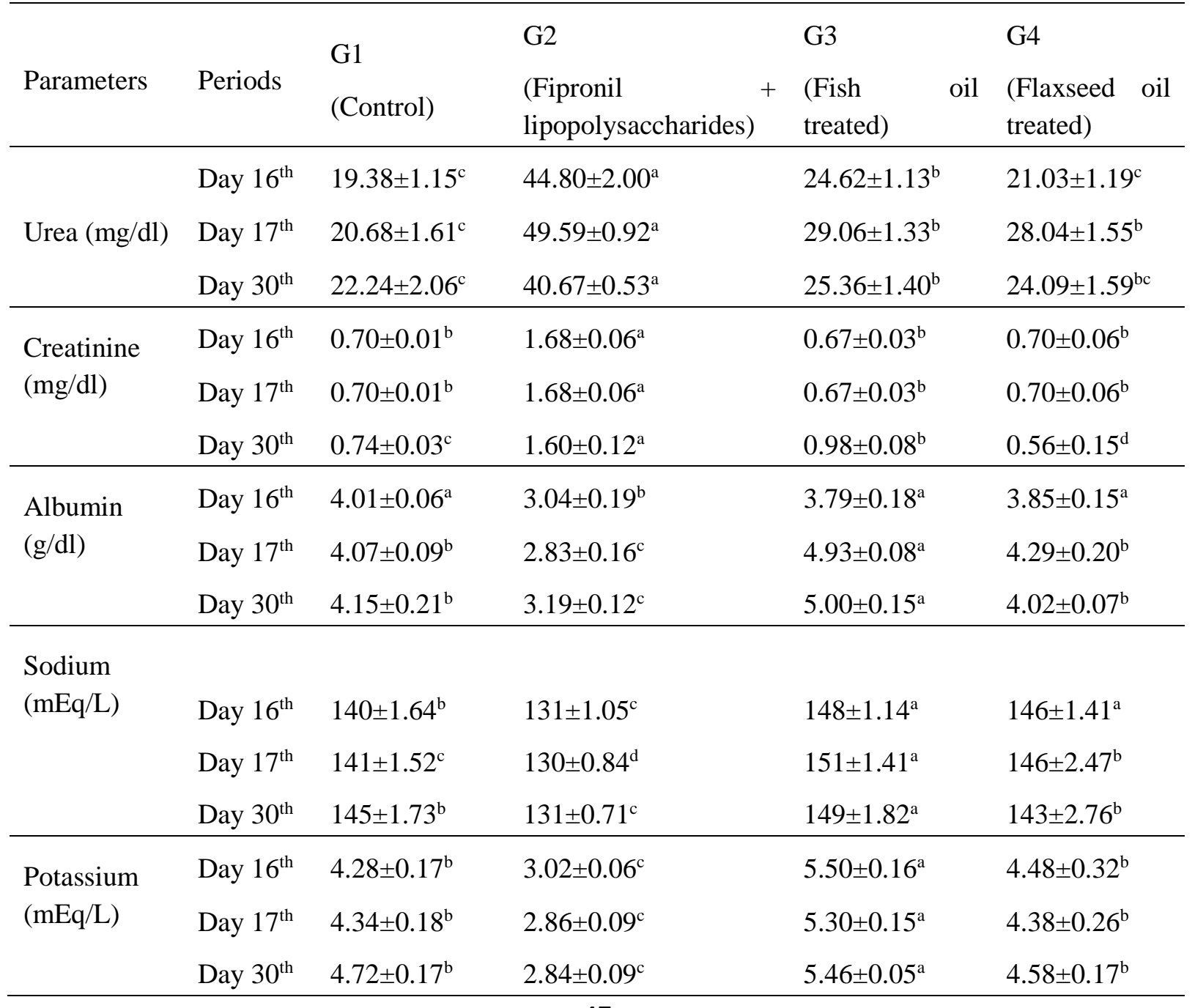


$\mathrm{a}, \mathrm{b} \& \mathrm{c}$ : There is no significant difference $(P>0.05)$ between any two means for the same attribute, within the same row have the same superscript letter. Data are presented as Mean $\pm \mathrm{SE}$. SE+ standard error.

Table 2: Changes of kidney L-MDA, SOD and GPx in control, Fipronil + lipopolysaccharides, fish oil and flaxseed oil treated groups at day $16^{\text {th }}$ and $30^{\text {th }}$.

\begin{tabular}{|c|c|c|c|c|c|}
\hline Parameters & Periods & $\begin{array}{c}\text { G1 } \\
\text { (Control) }\end{array}$ & $\begin{array}{c}\mathrm{G} 2 \\
\text { (Fipronil }+ \\
\text { lipopolysaccharides) } \\
\end{array}$ & $\begin{array}{c}\text { G3 } \\
\text { (Fish oil } \\
\text { treated) } \\
\end{array}$ & $\begin{array}{c}\mathrm{G} 4 \\
\begin{array}{c}\text { (Flaxseed oil } \\
\text { treated) }\end{array} \\
\end{array}$ \\
\hline MDA & Day $16^{\text {th }}$ & $0.12 \pm 0.02^{\mathrm{c}}$ & $0.37 \pm 0.03^{\mathrm{a}}$ & $0.23 \pm 0.03^{\mathrm{b}}$ & $0.18 \pm 0.02^{\mathrm{bc}}$ \\
\hline (nmol/ g tissue) & Day $30^{\text {th }}$ & $0.13 \pm 0.05^{\mathrm{c}}$ & $0.31 \pm 0.01^{\mathrm{a}}$ & $0.20 \pm 0.00^{\mathrm{b}}$ & $0.16 \pm 0.02^{\mathrm{bc}}$ \\
\hline SOD & Day $16^{\text {th }}$ & $0.34 \pm 0.02^{\mathrm{a}}$ & $0.21 \pm 0.01^{\mathrm{b}}$ & $0.22 \pm 0.03^{\mathrm{b}}$ & $0.23 \pm 0.01^{\mathrm{b}}$ \\
\hline (u/g. tissue) & Day $30^{\text {th }}$ & $0.38 \pm 0.04^{\mathrm{a}}$ & $0.16 \pm 0.02^{\mathrm{c}}$ & $0.21 \pm 0.00^{c}$ & $0.27 \pm 0.02^{\mathrm{b}}$ \\
\hline \multirow[t]{2}{*}{ GPx (ng/g. tissue) } & Day $16^{\text {th }}$ & $0.39 \pm 0.04^{\mathrm{a}}$ & $0.25 \pm 0.03^{b}$ & $0.25 \pm 0.01^{\mathrm{b}}$ & $0.29 \pm 0.02^{b}$ \\
\hline & Day $30^{\text {th }}$ & $0.35 \pm 0.04^{\mathrm{a}}$ & $0.19 \pm 0.01^{\mathrm{c}}$ & $0.23 \pm 0.01^{\mathrm{bc}}$ & $0.27 \pm 0.01^{\mathrm{b}}$ \\
\hline
\end{tabular}

$\mathrm{a}, \mathrm{b} \& \mathrm{c}$ : There is no significant difference $(P>0.05)$ between any two means for the same attribute, within the same row have the same superscript letter. Data are presented as Mean $\pm \mathrm{SE}$. SE+ standard error.

Table 3: Changes in serum TNF- $\alpha$ and IL-1 $\beta$ concentrations at day $17^{\text {th }}$ in different experimental animal groups.

\begin{tabular}{cccccc}
\hline Parameters & Periods & $\begin{array}{c}\text { G1 } \\
(\text { Control) }\end{array}$ & $\begin{array}{c}\text { G2 } \\
\text { (Fipronil }+ \\
\text { lipopolysaccharides) }\end{array}$ & $\begin{array}{c}\text { G3 } \\
\text { (Fish oil } \\
\text { treated) }\end{array}$ & $\begin{array}{c}\text { G4 } \\
\text { (Flaxseed oil } \\
\text { treated) }\end{array}$ \\
\hline TNF- $\alpha(\mathrm{pg} / \mathrm{ml})$ & Day $17^{\text {th }}$ & $0.09 \pm 0.01^{\mathrm{c}}$ & $0.37 \pm 0.03^{\mathrm{a}}$ & $0.21 \pm 0.01^{\mathrm{b}}$ & $0.16 \pm 0.02^{\mathrm{b}}$ \\
\hline $\mathrm{IL}-1 \beta(\mathrm{pg} / \mathrm{ml})$ & Day $17^{\text {th }}$ & $0.12 \pm 0.03^{\mathrm{c}}$ & $0.33 \pm 0.01^{\mathrm{a}}$ & $0.21 \pm 0.00^{\mathrm{b}}$ & $0.17 \pm 0.02^{\mathrm{bc}}$ \\
\hline
\end{tabular}

a, b \& c: There is no significant difference $(P>0.05)$ between any two means for the same attribute, within the same row have the same superscript letter. Data are presented as Mean \pm SE. SE+ standard error.

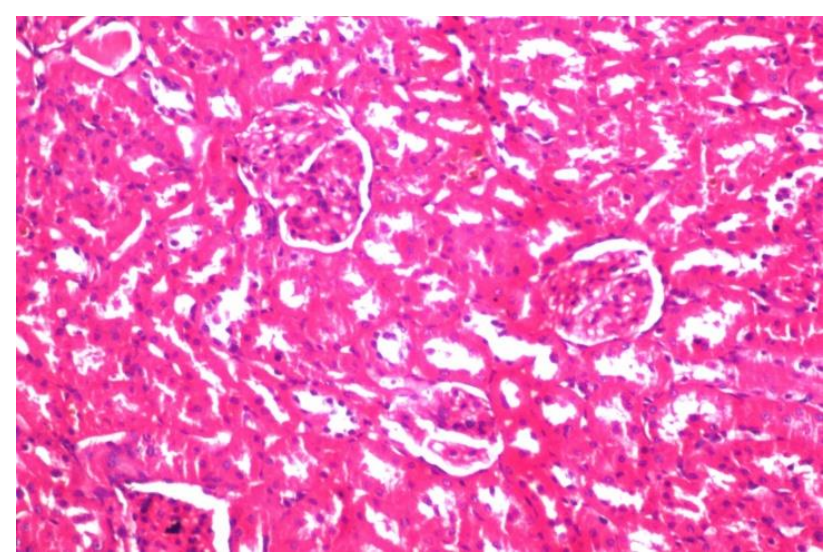

Fig.1. Photomicrograph of Control group at day $30^{\text {th }}$, showing normal histological structure of the kidney. H \& E stain x 100. 


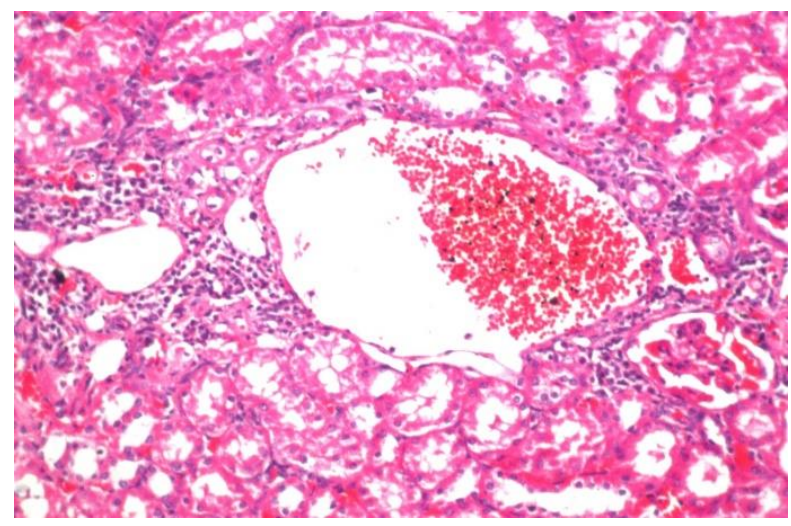

Fig.2. Photomicrograph of Fp + LPSs treated group at day $30^{\text {th }}$, showing severe congestion in renal blood vessels and glomerular tuft with focal mononuclear eosinophilic cellular infiltration in between the degenerated tubules. H \& E stain x 200.

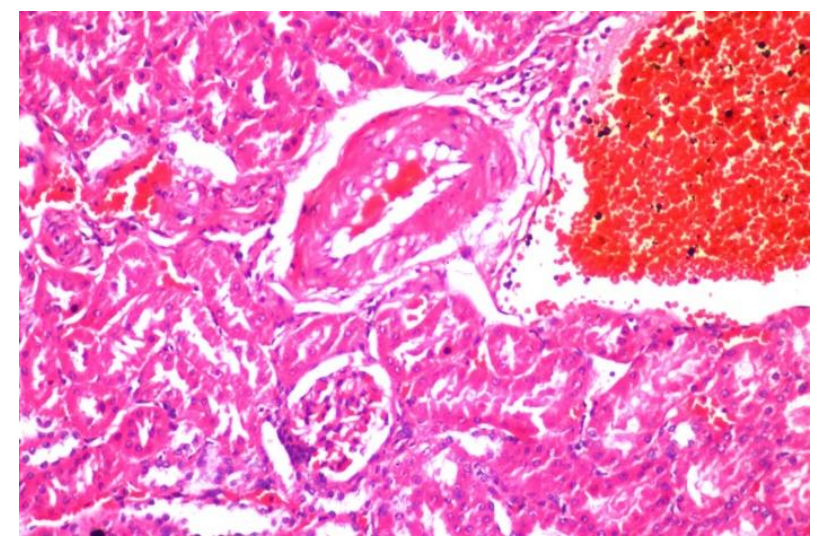

Fig.3. Photomicrograph of Fish oil treated group at day $30^{\text {th }}$, showing congestion in the renal blood vessels. H \& E stain x 200.

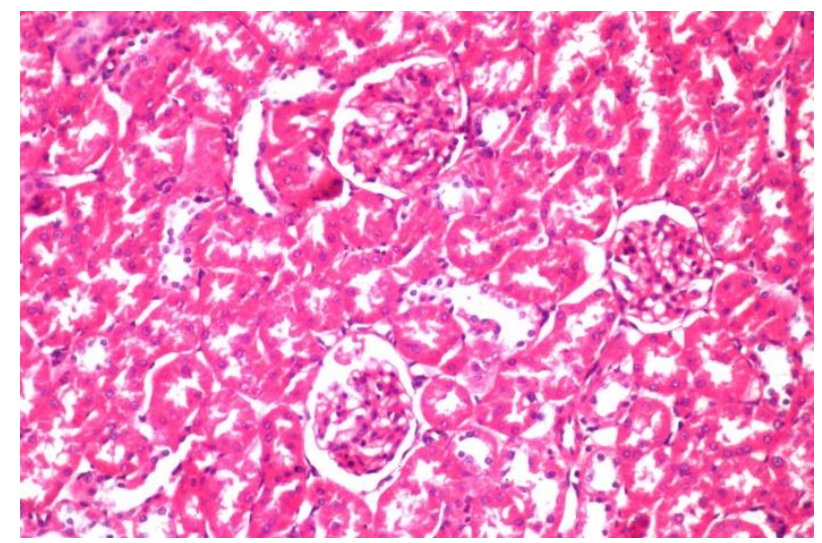

Fig.4. Photomicrograph of Flaxseed oil treated group at day $30^{\text {th }}$, showing mild degenerative changes in the form of vesiculation in glomerular tuft and mild degeneration of the epithelial cells lining the renal tubules. H \& E stain x 200.

\section{DISCUSSION}

In the present study, the obtained data showed a significant increase in urea and creatinine concentrations in rats administered Fp + LPSs compared to control group which come in agreement with the study of Prarabdh et al. (2014); Er and Dik (2014).

Prarabdh et al. (2014) rendered the increase in serum urea and creatinine concentrations to that fipronil compromised the ability of the 
kidney to filter waste products from blood. In addition, Er and Dik (2014) and Wen-Tien et al. (2010) illustrated that LPSs can induce hemodynamic changes and acute renal injury resulting in the reduction of glomerular filtration rate.

In fish oil treated group, there was a significant decrease in serum urea and creatinine concentrations compared to Fp + LPSs treated group. Similarily, De Caterina et al., (1993) documented that, administration of omega 3 causes an increase in plasma eicosapentaenoic acid (EPA) and docosahexaenoic acid (DHA) which is able to stimulate renal function. Some experimental studies have shown that omega 3 may increase thromboxane $\mathrm{A}_{3} \quad\left(\mathrm{Tx}_{3}\right)$ formation, with a fall in thromboxane $\mathrm{A}_{2}$ $\left(\mathrm{Tx}_{2}\right)$ and a significant increase in total prostacyclin levels. Thus this potential vasodilatory effect of $\omega 3$ may promote improved renal functions (Holm et al., 2001).

Flaxseed oil treated group revealed a significant decrease in urea and creatinine levels compared to Fp + LPSs treated group. This agree with the study of Khan et al. (2012) who suggested that omega-3 polyunsaturated fatty acids-enriched flaxseed oil attenuated the nephrotoxicity and oxidative damage induced by sodium nitroprusside intoxication. This also matches with the study of Omar (2016) who rendered this improvement of renal function to the antioxidant effect of flaxseed oil.

Concerning serum albumin concentration, the current study revealed significant decrease in Fp + LPSs treated group compared to control group. This comes in agreement with BalaliMood, (2008) who rendered the decrease in albumin to the decreased synthesis by the liver in response to insecticide exposure. Also Mackiewicz et al. (1992) stated that inflammatory hypoalbuminemia occurs because albumin is a negative acute phase protein and this may be related to the production of IL- 6 that increases the synthesis of acute-phase reactants by the hepatocytes while decreasing the production of albumin.

Fish oil treated group showed a significant increase in serum albumin level compared to Fp + LPSs treated group which come in agree with Hozayen et al. (2011) who rendered this to that fish oil treatment has the ability to restore the normal functional status of the poisoned liver and also protect against subsequent nephrotoxicity.

Flaxseed oil treatment also showed a significant increase in serum albumin level compared to Fp + LPSs treated group which come in harmony with the study of Farag et al., (2007) who suggested that this improvement could be returned to the relieving effects of flaxseed oil on hepatic architecture which is important for metabolism and excretion of toxic materials.

Referring to electrolytes, our study showed a significant decrease in serum $\mathrm{Na}^{+}$and $\mathrm{K}^{+}$ levels in rats administered $\mathrm{Fp}+$ LPSs compared to control group which come in agreement with Prasad et al. (2011) who attributed this to alterations in influx/efflux of electrolytes at the kidney in response to pesticide exposure. On contrast, fish oil treated group showed a significant increase in serum $\mathrm{Na}^{+}$and $\mathrm{K}^{+}$levels compared to $\mathrm{Fp}+$ LPSs treated group which matches the study of Mannaa et al. (2011) who said that this may be due to the fact that dietary fish oil rich in eicosapentanoic and docosahexaenoic fatty acids may prevent the changes in $\mathrm{Na}^{+} / \mathrm{K}^{+}$ATPase activity and by this mechanism prevent the membrane alteration.

Flaxseed oil significantly increased $\mathrm{Na}^{+}$and $\mathrm{K}^{+}$levels which come in agreement with Rizwan et al. (2014) who rendered this to that flaxseed oil improved integrity of renal 
proximal convoluted tubules and its brush border membrane which is responsible for reabsorption of important ions and that may be altered due to toxic insult.

Regarding to parameters of oxidative stress, our study showed significant increase in MDA level in Fp treated group compared to control group. This come in agreement with Bolton et al. (2000) and Banerjee et al. (1999) who said that this elevation could be attributed to the fact that $F p$ can be responsible for increase in the production of reactive oxygen species (ROS) in cells, which in turn result in increased lipid peroxidation levels and oxidative stress (Bolton et al., 2000 and Banerjee et al., 1999).

Also, the present study recorded a significant decrease in kidney tissue SOD and GPx activities in rats administered Fp compared to control group which come in harmony with the study of Mossa et al. (2015) who rendered this reduction to several causes as excess production of $\mathrm{O}_{2}^{-}$which is rapidly converted to $\mathrm{H}_{2} \mathrm{O}_{2}$ by SOD and to water by GPx, cellular injury and death of healthy cells that are able to respond to the oxidative insult as well as the insufficient detoxification capacity to Fp and damage caused by reactive oxygen species.

Fish oil treated group revealed a significant decrease in MDA level which matches the study of Gopal et al. (2011) who rendered this reduction to the ability of FO to inhibit lipid oxidation.

Concerning SOD and GPx as antioxidant enzymes, fish oil treatment showed a significant increase in their activities compared to Fp treated group. This comes in agreement with Priyamvada et al. (2014) and also with Mori and Beilin (2004) who illustrated that, omega 3 fatty acids upregulate gene expression of antioxidant enzymes and down-regulate genes associated with production of ROS. In addition, Ozgomen et al. (2000) suggested that the cause of this improvement is that $\omega 3$ PUFAs, which has been supplemented, may be replaced with PUFA components of the membranes that had been attacked by oxygen free radicals such as $\mathrm{O}_{2}{ }^{-}, \mathrm{H}_{2} \mathrm{O}_{2}$ and $\mathrm{OH}^{-}$.

Flaxseed oil treatment induced a significant decrease in MDA level and a significant increase in SOD and GPx activities in kidney tissues which come in harmony with Han et al. (2017) and Naqshbandi et al. (2012). Han et al. (2017) suggested that, the potential effect of flaxseed oil in preventing oxidative stress could be due to the ability to reduce free radical production or through increased free radical scavenging activity. On the other hand Makni et al. (2011) rendered these improvements to the relieving effects of flaxseed oil on hepatic and renal architectures which are important for metabolism and excretion of toxic materials.

Regarding to pro-inflammatory cytokines (TNF- $\alpha$ and IL-1 $\beta$ ), the current study revealed a significant increase in these cytokines in Fp + LPSs treated group compared to control group which come in agreement with Korish and Arafa (2011) and Wu et al. (2000). This may be due to bacterial LPSs acts on macrophages to release TNF- $\alpha$ and then the secreted TNF- $\alpha$ induces the cells to produce IL-1 $\beta$ and IL-6 as stated by Jean-Baptiste (2007) and Xaus et al. (2000). On the other hand, fish oil treated group showed a significant decrease in TNF- $\alpha$ and IL- $1 \beta$ compared to Fp + LPSs treated group which agree with Cao et al. (2011). This can be attributed to inhibition of the activation of nuclear factor $\kappa \mathrm{B}(\mathrm{NF} \kappa \mathrm{B})$ that down-regulate the inflammatory response (Novak et al. 2003 and Calder, 2010). Meanwhile, flaxseed oil treated group showed a significant decrease in TNF- $\alpha$ and IL- $1 \beta$ concentrations compared to 
Fp + LPSs treated group which agree with Archana et al. (2010).

The possible explanation may be attributed to $\alpha$-linolenic acid (ALA) in the oil which could diminish the production of pro-inflammatory cytokines as stated by James et al. (2000). Also Ren and Chung (2007) rendered the down-regulation of TNF-alpha gene expression to that ALA can block the activation of nuclear factor-kappa $\beta$ and mitogen-activated protein kinases in lipopolysaccharide stimulated cells.

Concerning histopathological alterations, the present study revealed congestion in inter tubular blood vessels and tufts of the glomeruli with focal inflammatory cells infiltration in between the degenerated tubules in Fp + LPSs treated group which come in agreement with Mossa et al. (2015); Budin et al. (2013) and Abdel-Mottaleb and Zaki. (2008). Fish oil treated group when compared to Fp + LPSs treated group showed fewer infiltration with inflammatory cells and also lesser congestion of blood vessels which come in harmony with the study of Hussein et al. (2013) and Hozayen et al. (2011). Flaxseed oil treated group in the current study revealed no histopathological alterations which agree with the study of Omar (2016); Abdel Moneima et al. (2011) and Farag et al. (2007).

\section{Conclusion}

It could be concluded that flaxseed oil and fish oil are effective in improving the oxidative and inflammatory state generated by administration of fipronil and lipopolysaccharides, taking into consideration that flaxseed oil is more effective than fish oil.

\section{REFERENCES}

Abdel Moneim, A.E.; Dkhil, M.A. and AlQuraishy, S. (2011): The protective effect of flaxseed oil on lead acetateinduced renal toxicity in rats. J. Hazardous Mater., 194: 250-255.

Abdel-Mottaleb, E. M., and Zaki, H. M. (2008): Studies on the effect of garlic preparation on E.Coli O157:H7 causing enteritis in lambs. Egypt. J. Comp. Path \& Clinic. Path. Vol. 21 No 4., p 102 - 129.

Andrade K.Q.; Moura F.A.; dos Santos J.M.; de Araújo O.R.P.; Santos J.C.D.F. and Goulart M.O.F. (2015): Oxidative stress and inflammation in hepatic diseases: therapeutic possibilities of $\mathrm{N}$ acetylcysteine. International Journal of Molecular Sciences; 16(12): 30269 30308.

Anilla, L. and Vijayalaskshmi, N.R. (2002): Flavonoids from Emblica officinalis and Mangifera indica: effectiveness for dyslipidemia. J Ethanopharmacol; 79: 81-87.

Archana, S.; Kusum, H.; Harsh, M.; Raj, P.; Singh, P. and Sanjay, C. (2010): Longterm flaxseed oil supplementation diet protects BALB/c mice against Streptococcus pneumoniae infection Med Microbiol Immunol.; 199: 27 34. DOI 10.1007/s00430-009-0132-7

Balali-Mood, M. and Balali-Mood, K. (2008): Neurotoxic disorders of organophosphorus compounds and their managements (review article). Arch Iran Med. (1): 65-89.

Banerjee, B.D.; Seth, V.; Bhattacharya, A; Pasha, S.T. and Chakraborty, A.K. (1999): Biochemical effects of some pesticides on lipid peroxidation and free radical scavengers. Toxicol Lett 107: 33 - 47. 
Bolton, J.T.; Trush, M.A.; Penning, T.M.; Dryhurst, G. and Monks, T.J. (2000): Role of quinones intoxicology. Chem Res Toxicol 13: 135-160.

Budin, S.B.; Han, K.J.; Jayusman, P.A.; Taib, I.S.; Ghazali, A.R. and Mohamed, J. (2013): Antioxidant activity of to cotrienol rich fraction prevents insecticides-induced renal damagein rats. J Toxicol Pathol.; 26: 111 - 118 .

Calder, P.C. (2010): Omega-3 fatty acids and inflammatory processes. Nutrients, 2(3): $355-374$.

Cao, S.; Ren, J.; Sun, L.; Gu, G.; Yuan, Y. and Li J. (2011): Fish oil-supplemented parenteral nutrition prolongs survival while beneficially altering phospholipids' Fatty Acid composition and modulating immune function in rat sepsis. Shock.; 36:184-190.

Cohen, S.L.; Moore, A.M. and Ward, W.E. (2005): Flaxseed oil and inflammationassociated bone abnormalities in interleukin-10 knockout mice. J Nutr Biochem.; 16 (6): 368 - 374.

De Caterina, R.; Caprioli, R.; Giannesi, D.; Sicari, R.; Galli, G.; Lazzerini, G.; Bernini, W.; Carr, L. and Rindi, P. (1993): N-3 fatty acids reduce proteinuria in patients with chronic glomerular disease. Kidney Int, 44: 843-850.

Er, A. and Dik, B. (2014): The effects of florfenicol on the values of serum TNF- $\alpha$ and other biochemical markers in LPS-induced endotoxemia in brown trout. Mediators of Inflammation. 2014: 5.

Farag, M.F.; Younis, B.M. and Hafez, S. E. (2007): Role of flaxseed oil in modulating hematological, biochemical and histopathological disorders induced by allura dye in rats. Isotope and Radiation Research; v. 39(4): p. 9931003.

Frudenberg, M.A. and Galanos, C. (1990): Bacterial lipopolysac-charides: structure, metabolism and mechanism of action. International Reviews of immunology 6; 207-221.

Goldfarb, A.H. (1993): Antioxidants: role of supplementation to prevent exerciseinduced oxidative stress. Medicine and Science in Sports and Exercise, 25(2): 232-236.

Gopal, K.M.; Mohan, J.; Meganathan, M.; Sasikala, P.; Gowdhaman, N.; Balamurugan, K.; Nirmala, P. and Santhakumari, A.S. (2011): Effect of dietary fish oil (Omega-3-fatty acid) against oxidative stress in isoproterenol induced myocardial injury in albino wistar rats. Global J. of Pharmacol. 5: 04-06.

Han,H.; Fubin, Q.; Haifeng, Z.; Haiying, T.; Xiuhua, L. and Dongxing, S. (2017): Dietary Flaxseed Oil Prevents WesternType Diet-Induced Nonalcoholic Fatty Liver Disease in Apolipoprotein-E Knockout Mice. Oxidative Medicine and Cellular Longevity. Volume 2017, Article ID 3256241, 13 pages.

Henry, R.J. (1974): Clin. Chem., Harper \& Row New York, Sec. Edit. 643-646.

Holm, T.; Andreassen, A.K. and Aukrust, P., et al. (2001): Omega-3 fatty acids improve blood pressure control and preserve renal function in hypertensive heart transplant recipients. Eur Heart 1; 22: 428 - 36.

Hozayen, W.; Bastawy, M. and Elshafeey, H. (2011): Effects of aqueous purslane 
(Portulaca Oleracea) extract and fish oil on gentamicin nephrotoxicity in albino rats. Nature Sci., 9: 47-62.

Hussein, S.A.; Ragab, O.A. and El-Eshmawy, M.A. (2013): Protective effect of dietary fish oil on cyclosporine induced nephrotoxicity in Rats, Benha Veterinary Medical Journal, vol. 25, No. 2: $218-231$.

Hussein, S.A.; El-Senosi, Y.A.; Ragab, M.R. and Mohammed M.F. (2014): Beneficial effect of flaxseed oil on lipid metabolism in high cholesterol diet fed rats, Benha Veterinary Medical Journal, Vol. 27, No. 2 : 290-301.

Jaffe, A. (1986): “Technological opportunity and spillovers of R\&D: Evidence from firms' patents, profits, and market value." Am. Econ. Rev.; 76: 984 1001.

James, M.J.; Gibson, R.A. and Cleland, L.G. (2000): Dietary polyunsaturated fatty acids and inflammatory mediator production. Am J Clin Nutr 71(suppl): 343S-348S.

Jean-Baptiste, E. (2007): Cellular mechanisms in sepsis. J Intensive Care Med 22:63-72.

Kaplan, A. (1984): Clin Chem The C.V. Mosby Co. St Louis Toronto. Princeton; 1257-1260 and 437 and 418.

Khan, M.W.; Privamvada, S.; Khan, S.A.; et al. (2012): Protective effect of -3 polyunsaturated fatty acids (PUFAs) on sodium nitroprusside-induced nephrotoxicity and oxidative damage in rat kidney. Hum. Exp. Toxicol.; 31(10): 1035-1049.

Khan, S.; Jan, M.H.; Kumar, D. and Telang, A.G. (2015): Firpronil induced spermotoxicity is associated with oxidative stress, DNA damage and apoptosis in male rats. Pestic Biochem Physiol. 124:8-14.

Korish, A.A. and Arafa, M.M. (2011): Propolis derivatives inhibit the systemic inflammatory response and protect hepatic and neural cells in acute septic shock. Braz J Infect Dis 2011; 15(4):332-338.

Lam, P.; Cheung, F.; Tan, H.Y.; Wang, N.; Yuen, M.F. and Feng, Y.B. (2016): Hepatoprotective effects of Chinese medicinal herbs: a focus on antiinflammatory and anti-oxidative activities. International Journal of Molecular Sciences. 17(4): p. 465.

Mackiewicz, A.; Schooltink, H.; Heinrich, P.C. and Rose-John, S. (1992): Complex of soluble human IL-6receptor/IL-6 up-regulates expression of acute-phase proteins. J Immunol.; 149: 2021-2027.

Makni, M.; Fetoui, H.; Gargouri, N.K.; Garoui, M. and Zeghal, N. (2011): Antidiabetic effect of flax and pumpkin seed mixture powder: Effect on hyperlipidemia and antioxidant status in alloxan diabetic rats. Journal of Diabetes and its Complications, 25, 339-345.

Mannaa, F.; El-Shamy, K. A., El- Shaikh, K. A.; El-Kassaby, M. (2011): Efficacy of fish liver oil and propolis as neuroprotective agents in pilocarpine epileptic rats treated with valproate. Pathophysiology; 699: 1 - 8.

Mittal, M.; Siddiqui, M.R.; Tran, K.; Reddy, S.P. and Malik, A.B. (2014): Reactive oxygen species in inflammation and 
tissue injury. Antioxidants and Redox

Signaling. 20(7): $1126-1167$.

Mori, T.A. and Beilin, L.J. (2004): Omega-3 fatty acids and inflammation. Curr Atheroscler Rep.; 6: 461 - 467.

Mossa, A.T.H.; Swelam, S.E. and Mohafrash, S.M.M. (2015): Sub-chronic exposure to fipronil induced oxidative stress, biochemical and histotopathological changes in the liver and kidney of male albino rats, Toxicol. Rep., (10): 202209.

Muga and Chao (2014): Effects of fish oil and spirulina on oxidative stress and inflammation in hypercholesterolemic hamsters. Muga and Chao BMC Complementary and Alternative Medicine, 14: 470.

Naqshbandi, A.; Khan, W.; Rizwan, S. and Khan, F.(2012): Studies on the protective effect of flaxseed oil on cisplatin-induced hepatotoxicity. Hum. Exp. Toxicol.; 31: 364-375.

Newairy, A.S. and Abdou, H.M. (2009): Protective role of flax lignans against lead acetate induced oxidative damage and hyperlipidemia in rats. Food Chem Toxicol 47(4):813-818.

Nobre, M.E.P., Correia, A.O.; Borges, M.B.; Sampaio, T.M.A.; Chakraborty, S.A.; Gonçalves, D.O.; Brito, G.A.C.; Leal, L.K.A.M.; Felipe, C.F.B.; Lucetti, D.L.; Arida, R.M. and Viana, G.S.B. (2013): Eicosapentaenoic acid and docosahexaenoic acid exert antiinflammatory and antinociceptive effects in rodents at low doses, Nutr. Res. 33: $422-433$.

Novak, T.E.; Babcock, T.A.; Jho, D.H.; Helton, W.S. and Espat, N.J. (2003): NF-B inhibition by omega- 3 fatty acids modulates LPS-stimulated macrophage TNF-alpha transcription, Am. J. Phys. Lung Cell. Mol. Phys. 284: L84 -L89.

Omar, Sh.A.M. (2016): The potential protective influence of flaxseed oil against renal toxicity induced by thioacetamide in rats. Saudi Journal of Biological Sciences (2016), http://dx.doi.org/10.1016/j.sjbs.2016.09 .021 .

Ozgomen, S., AtalayCatal, S.; Ardicoglu, O. and Kamanli, A. (2000):'Effect of omega-3fatty acids in the management of fibromyalgia syndrome, Int. J. Clin. Pharm. Ther., 38: 362-363.

Prarabdh, C.; Badgujar, N. N.; Pawar, G. A.; Chandratre, A.G. Telang and Sharma A.K. (2014): Fipronil induced oxidative stress in kidney and brain of mice: Protective effect of vitamin $\mathrm{E}$ and vitamin $\mathrm{C}$, Pesticide Biochemistry and Physiology; http://dx.doi.org/doi: 10.1016/j.pestbp.2014.10.013.

Prasad, M.; Kumar, A.; Mishra, D.; Srivastav, S.K. and Srivastav, A.K. (2011): Alterations in blood electrolytes of a freshwater catfish Heteropneustes fossilis in response to treatment with a botanical pesticide, Nerium indicum leaf extract. Fish Physiol Biochem. 2011 Sep; 37(3): 505 - 510.

Priyamvada, S.; Tabrez, S.; Priyadarshini M. (2014): Gene-environment interactions in heavy metal and pesticide carcinogenesis, Mutation Research/Genetic Toxicology and Environmental Mutagenesis 2014; 760:1-9.

Ren, J. and Chung, S.H. (2007): Antiinflammatory effect of alpha-linolenic 
acid and its mode of action through the inhibition of nitric oxide production and inducible nitric oxide synthase gene expression via NF-kappa B and mitogen-activated protein kinase pathways. J Agric Food Chem; 55 (13): 5073-5080

Rizwan, S.; Naqshbandi, A.; Zeba Farooqui, Z.; Khan, A.A. and Khan F. (2014): Protective effect of dietary flaxseed oil on arsenic-induced nephrotoxicity and oxidative damage in rat kidney. Food and Chemical Toxicology; 68: 99-107.

Seki, E. and Schwabe, R.F. (2015): Hepatic inflammation and fibrosis: functional links and key pathways. Hepatology; 61(3):1066-1079.

Takamiya, T.; Hosobuchi, S.; Noguchi, N.; Paterson, A.H.; Iijima, H.; Murakami, Y. and Okuizumi, H. (2009): The application of restriction landmark genome scanning (RLGS) method for surveillance of non-Mendelian inheritance in F1 hybrids Comparative and Functional Genomics. Comparative and Functional Genomics, 2009:6.

Tingle, C.C.D.; Rother, J.A.; Dewhurst, C.F.; Lauer, S. and King, W.J. (2003): Fipronil: environmental fate, ecotoxicology, and human health concerns. Rev. Environ. Contam. Toxicol.; $176: 1$ - 66.

Valko, M.; Rhodes, C.J.; Moncol, J.; Izakovic, $\mathrm{M}$. and Mazur, $\mathrm{M}$. (2006): Free radicals, metals and antioxidants in oxidative stress-induced cancer. Chem. Biol. Interact.; 160: 1 40.

Vijaimohan, K.; Jainu, M.; Sabitha, K.E.; Subramaniyam, S.; Anandhan, C. and
Shyamala Devi, C.S. (2006): Beneficial effects of alpha linolenic acid rich flaxseed oil on growth performance and hepatic cholesterol metabolism in high fat diet fed rats. Life Sci; 79(5): 448 - 454.

Wen-Tien, W.; Tsung-Ming, H.; Nien-Tsung, L.; Yi-Manu, S.; Ru-Ping, L. and Bang-Gee, H. (2010): Low dose erythropoietin aggravates endotoxininduced organ damage in conscious rats. Cytokine, 49 (2): 155-62.

Wu, C.; Wang, X.; Gadina, M.; O'Shea, J.J.; Presky, D.H. and Magram, J. (2000): IL-12 receptor beta 2 (IL-12R beta 2)-deficient mice are defective in IL-12-mediated signaling despite the presence of high affinity IL-12 binding sites. J. Immunol. 165:6221-6228.

Xaus, J.; Comalada, M.; Valledor, A.F.; Lloberas, J.; Lo'pez-Soriano, F.; Argile's, J.M.; Bogdan, C. and Celada, A. (2000): LPS induces apoptosis in macrophages mostly through the autocrine production of TNF- Blood 95:3823-3831.

Young, D.S. (1995): Effects of Drugs on Clinical Laboratory Tests. $4^{\text {th }}$ Edn., AACC Press, Washington, D.C. 